\title{
Kumeyaay Ethnobotany: Shared Heritage of the Californias. By Michael Wilken-Robertson. 2018. Sunbelt Publications, San Diego. 281 pp.
}

\author{
Nemer E. Narchi ${ }^{1 *}$ \\ ${ }^{1}$ Centro de Estudios en Geografía Humana, El Colegio de Michoacán, La Piedad, Mexico. \\ *narchi@colmich.edu.mx
}

Received February 8, 2019

OPENӘACCESS

Accepted March 19, 2019

DOI 10.14237/ebl.10.1.2019.1521

Published April 17, 2019

Copyright (c) 2019 by the author(s); licensee Society of Ethnobiology. This is an open-access article distributed under the terms of the Creative Commons Attribution-NonCommercial 4.0 International Public License (https://creativecommons.org/licenses/by-nc/4.0), which permits non-commercial use, distribution, and reproduction in any medium, provided the original author and source are credited.

Anyone traveling from San Diego, California to Ensenada, Mexico will be mesmerized by the coastal shrub landscapes of the California Floristic Province, the patches of Sonoran Desert vegetation, and how these contrast with the Pacific Ocean to the west. Some 1300 years ago, these landscapes were occupied by western Yuman hunter-gatherers such as the Kumeyaay. Presently, Kumeyaay descendants live in scattered populations along the northernmost part of Baja California and in San Diego County. After 1848, Kumeyaay territories were altered by the imposition of a binational border. This process gradually forced Kumeyaay communities in Mexico and the United States to adopt different political, cultural, and economic structures. Presently, Mexico-bound Kumeyaay represent a relatively small group of some 600 people in five rural indigenous communities in Baja California. Among these, some 70 people are fluent speakers of their language, most of them elders or middle aged.

Language and knowledge loss among Kumeyaay youth would be enough to make a case for the uttermost importance for research such as that portrayed in Kumeyaay Ethnobotany. The book is divided into nine chapters, plus an introduction and an appendix. These chapters range from describing Baja California prehistory to offering ways in which to put living knowledge to work. For the purpose of this review, I will cluster the book into three major sections.

Section one helps the readers to get to know and familiarize themselves with the rich environmental, ecological, and anthropological settings of the Baja California Peninsula, Kumeyaay ethnohistory, current ethnography, and language. The section transports the reader into a land of diverse landscapes and biota. The section also offers a vivid description of the rapid changes suffered by the peoples of Baja California since European contact and up to the 21st century. Kumeyaay origin mythologies are well presented and allow readers to fully appreciate a deep connection between people, plants, and environment. These narratives are followed by a recollection of traditional Kumeyaay economic landscapes along with a brief introduction to the plant material culture and materia medica (botanicals used in the practice of medicine). Lastly, the section describes contemporary Kumeyaay communities in Mexico. In addition, a thorough explanation of the language's linguistic ties, pronunciation, and current status is offered.

Section two begins by building on the sources and methods used throughout the research. I appreciate the author's detailed writing that attests to the methods he used for collecting data, details the nature and quality of archival material, and acknowledges the strengths and limitations of the methods and sources used. The second part of this section presents the plant materials collected. The author focused solely on Kumeyaay and Ko'alh use of native plants. His criteria are thoughtful and sound as most of the plant communities in northern Baja California have existed since the early Holocene, potentially representing some of the first human-plant interaction in the region. In addition, a number of these plants are currently endangered, and the author expects to raise public support for their conservation along with deeper appreciation for the environmental services these plants provide. The second part of this 
section, the Catalog of Native Plants and Their Uses is the longest chapter of the book. Over 130 pages long, the chapter summarizes information on the past and present uses of 47 plants. One of the most remarkable examples is coast agave (Agave shawii), an ancient source of food and fiber. The ethnobotanical entries are not limited to portraying the knowledge of the 16 highly valuable informants that the author relied on, as these also include ethnohistorical and ethnoarchaeological information from other sources. While I think it is impressive to generate such a vast amount of intimate knowledge for 47 plants, I am convinced that section three represents what is really important from this research. The section takes a bold stance, asking: "What is worthy within this research for the future?" Here, the applied anthropological practice of the author through the years answers the question. For example, his involvement in the planning and maintenance of a Community Museum and Botanical Gardens in Tecate, Baja California, a place designed and managed through active participatory community involvement. Additionally, ethnobiological research becomes relevant, as the section shows, when research results, activism, and advocacy help to ensure that indigenous plant specialists and traditional artisans and teachers can regularly transmit their knowledge in their own communities. These local conversations and plans can then permeate into local, regional, and national imaginaries so as to extinguish long-held perceptions of 'development' with associated notions of Stateimposed solutions for environmental degradation. Finally, the high aesthetic value of the illustrations in the book cannot go unmentioned. The publishers have gone above and beyond with regards to paper and printing quality, allowing for the reader's immersion in beautiful and vivid daily life scenes among the Kumeyaay through the lenses of the author and other three talented photographers, including those of California State University Professor Deborah Small.

As an anthropologist, I have always been strongly biased towards appreciating research dealing with small societies and disappearing languages. These interests become especially strong when research revolves around the biocultural strategies that nonagriculturalists have developed to adapt and thrive under harsh environmental conditions. That is the case of Michael Wilken-Roberton's Kumeyaay Ethnobotany. A book whose main contribution lies not in presenting a wonderful and millennial people-plant relationship, which it does, but in raising a scientifically sound argument that can be, and should be, used in reviving local traditions and cultures while also advocating for the highly pertinent inclusion of ethnobiological knowledge in the conservation of postglacial socio-ecological systems as delicate as those found in the southern California-northern Baja California complex. 